\title{
Internet-Enabled Mobile Handheld Devices for Mobile Commerce
}

\author{
Wen-Chen $\mathrm{Hu}$ \\ University of North Dakota \\ E-Mail: wenchen@cs.und.edu \\ Jyh-haw Yeh \\ Boise State University \\ E-Mail: jhyeh@cs.boisestate.edu \\ Hung-Ju Chu \\ University of Florida \\ E-Mail: hchu@cise.ufl.edu \\ Chung-wei Lee \\ Auburn University \\ E-Mail: chwlee@eng.auburn.edu
}

\begin{abstract}
The emergence of wireless and mobile networks has made possible the introduction of electronic commerce to a new application and research area: mobile commerce. Internet-enabled mobile handheld devices are one of the core components of a mobile commerce system, making it possible for mobile users to directly interact with mobile commerce applications. Much of a mobile user's first impression of the application will be formed by his or her interaction with the device, therefore the success of mobile commerce applications is greatly dependent on how easy they are to use. This article first explains the role of handheld devices in mobile commerce systems and then discusses the devices in detail. A mobile handheld device includes six major components: i) a mobile operating system, ii) a mobile central processor unit, iii) a microbrowser, iv) input/output devices, v) a memory, and vi) batteries. Each component is described in detail and major products and technologies for the component are given. The technology needed for synchronization with desktop PCs and various mobile commerce applications is also presented.
\end{abstract}

Key words: Mobile Commerce, Internet

\section{INTRODUCTION}

With the introduction of the World Wide Web, electronic commerce has revolutionized traditional commerce and boosted sales and exchanges of merchandise and information. Recently, the emergence of wireless and mobile networks has made possible the extension of electronic commerce to a new application and research area: mobile commerce, which is defined as the exchange or buying and selling of commodities, services, or information on the Internet 
through the use of mobile handheld devices. In just a few years, mobile commerce has emerged from nowhere to become the hottest new trend in business transactions. Despite a weak economy, the future of mobile commerce is bright according to the latest predictions:

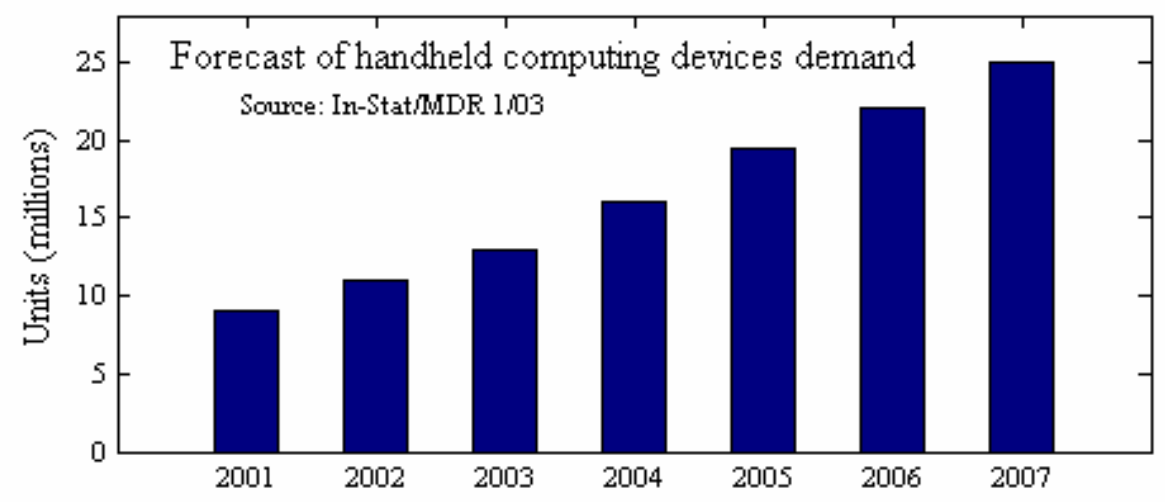

Figure 1: Forecast of demand for mobile handheld computing devices

- Figure 1 shows the growth in demand for handheld computing devices (not including smart cellular phones) through 2007, as predicted by the research firm In-Stat/MDR (PalmInfocenter.com, 2003).

- It is estimated that 50 million wireless phone users in the United States will use their handheld devices to authorize payment for premium content and physical goods at some point during the year 2006. This represents 17 percent of the projected total population and 26 percent of all wireless users (Reuters, 2001).

- Mobile commerce is an effective and convenient way of delivering electronic commerce to consumers from anywhere and at any time. Realizing the advantages to be gained from mobile commerce, companies have begun to offer mobile commerce options for their customers in addition to the electronic commerce they already provide (The Yankee Group, 2002).

A mobile commerce system involves a variety of components, among which mobile handheld devices feature largely as they provide the equipment mobile users need to interact with mobile commerce applications. Therefore, much of a mobile user's first impression of the application comes from how easy the devices are to use. The success of mobile commerce applications is thus greatly dependent on the devices. This paper discusses mobile handheld devices and their role in mobile commerce. A handheld device includes six major components: i) a mobile operating system, ii) a mobile central processing unit, iii) a microbrowser, iv) input/output devices, v) a memory, and vi) batteries. The six components, along with synchronization with desktop PCs and peripherals, are described in detail and their related technologies and products are introduced. Mobile commerce applications are also discussed. 


\section{Requirements of a Mobile Handheld Device}

It is first necessary to examine which of features a handheld device is expected to have in order to conduct effective and efficient mobile commerce transactions and the challenges that must be overcome in the process of developing new mobile handheld devices. The requirements for a mobile handheld device are:

- It should be small enough to be held in one hand.

- Input methods must be easy to use and learn.

- The screen must be large enough for mobile users to read the contents effortlessly and use the stylus without difficulty.

- Processors should be powerful enough to process users' requests with short latencies, while at the same time consuming less power to lengthen the battery life.

- Maximum interoperability is desirable because many technologies are now available for handheld devices and new techniques are constantly being introduced.

- The memory must be large enough for most mobile commerce applications.

- Battery life must be sufficient for operations lasting several hours before the batteries need to be recharged.

- Synchronization with desktop PCs or peripherals should be convenient and easy.

\section{MOBILE COMMERCE SYSTEMS}

Internet-enabled mobile handheld devices play a crucial role in mobile commerce, as they are the devices with which mobile users interact directly with mobile commerce applications. This section first introduces a mobile commerce system and then illustrates how it is used to carry out a mobile transaction.

\section{System Structure}

A mobile commerce system is inherently interdisciplinary and could be implemented in various ways. Figure 2 shows the structure of a mobile commerce system and a typical example of such a system (Hu, Lee, \& Yeh, 2003). The system structure includes six components: i) mobile commerce applications, ii) mobile handheld devices, iii) mobile middleware, iv) wireless networks, v) wired networks, and vi) host computers.

1. Mobile commerce applications: Electronic commerce applications are numerous, including auctions, banking, marketplaces and exchanges, news, recruiting, and retailing, to name but a few. Mobile commerce applications not only cover the electronic commerce applications, but also include new applications, which can be performed at any time and from anywhere by using mobile computing technology, for example, mobile inventory tracking.

2. Mobile handheld devices: An Internet-enabled mobile handheld device is a small generalpurpose, programmable, battery-powered computer that is capable of handling the front end of mobile commerce applications and can be operated comfortably while being held in one hand. It is the device with which mobile users interact directly with mobile commerce applications.

3. Mobile middleware: The term middleware refers to the software layer between the operating system and the distributed applications that interact via the networks. The primary mission of a middleware layer is to hide the underlying networked environment's complexity by 
insulating applications from explicit protocols that handle disjoint memories, data replication, network faults, and parallelism (Geihs, 2001). The major task of mobile middleware is to seamlessly and transparently map Internet contents to mobile stations that support a wide variety of operating systems, markup languages, microbrowsers, and protocols. WAP and imode are the two major kinds of mobile middleware. According to an article in Eurotechnology.com (Eurotechnology Japan K. K., 2002), 60 percent of the world's wireless Internet users use i-mode (NTT DoCoMo, n.d.), 39 percent use WAP (Wireless Application Protocol Forum Ltd., n.d.), and 1 percent use Palm middleware. Table 1 compares i-mode and WAP.

4. Wireless and wired networks: Wireless communication capability supports mobility for end users in mobile commerce systems. Wireless LAN, MAN, and WAN are the major components used to provide radio communication channels so that mobile service is possible. In the WLAN category, the Wi-Fi standard with 11 Mbps throughput dominates the current market. However, it is expected that standards with much higher transmission speeds, such as IEEE 802.11a and 802.11g, will replace Wi-Fi in the near future. Compared to WLANs, cellular systems can provide longer transmission distances and greater radio coverage, but suffer from the drawback of much lower bandwidth (less than $1 \mathrm{Mbps}$ ). In the latest trend for cellular systems, 3G standards supporting wireless multimedia and high-bandwidth services are beginning to be deployed.

5. Host computers: A user request such as database access or updating is actually processed at a host computer, which contains three major kinds of software: i) Web servers, ii) database servers, and iii) application programs and support software.

Table 1: Comparisons of the two major types of mobile middleware

\begin{tabular}{|l|l|l|}
\hline & \multicolumn{1}{|c|}{ WAP } & \multicolumn{1}{c|}{ i-mode } \\
\hline \multicolumn{1}{|c|}{ Developer } & WAP Forum & NTT DoCoMo \\
\hline Function & A protocol & A complete mobile Internet service \\
\hline Host Language & $\begin{array}{l}\text { WML (Wireless Markup } \\
\text { Language) }\end{array}$ & CHTML (Compact HTML) \\
\hline Major Technology & WAP Gateway & TCP/IP modifications \\
\hline Key Features & Widely adopted and flexible & Highest number of users and easy to use \\
\hline
\end{tabular}




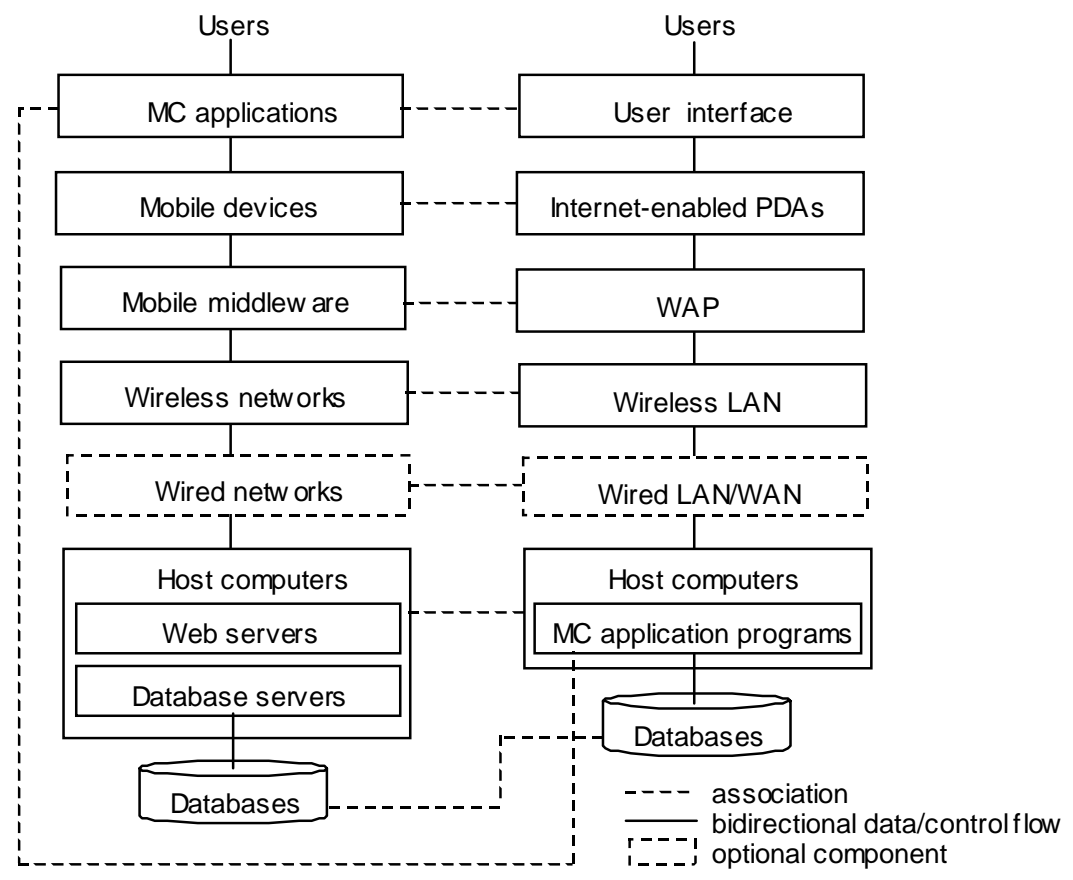

An MC System Structure A Typical Implemention

Figure 2: A mobile commerce system structure

\section{An Example of Mobile Commerce Transaction Processing}

To explain how the mobile commerce components work together, Figure 3 shows a flowchart of how a user request is processed by the components in a mobile commerce system, along with brief descriptions of how each component processes the request. 


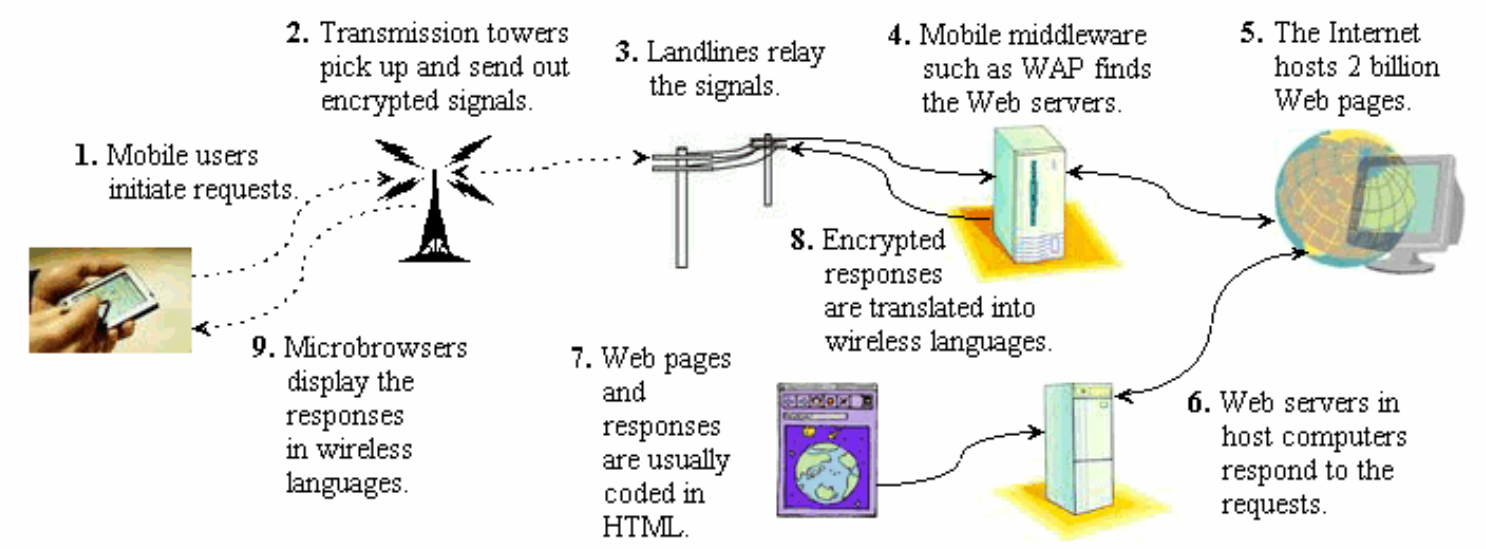

Figure 3: A flowchart of a user request processed in a mobile commerce system

1. Mobile commerce applications: A content provider implements an application by providing two sets of programs: client-side programs, such as user interfaces on microbrowsers, and server-side programs, such as database access and updating.

2. Mobile handheld devices: Handheld devices present user interfaces to the mobile end users, who specify their requests on the interfaces. The devices then relay the user requests to the other components and later display the processing results using the interfaces.

3. Mobile middleware: The major purpose of mobile middleware is to seamlessly and transparently map Internet contents to mobile stations that support a wide variety of operating systems, markup languages, microbrowsers, and protocols. Most mobile middleware also encrypts the communication in order to provide some level of security for transactions.

4. Wireless networks: Mobile commerce is possible mainly because of the availability of wireless networks. User requests are delivered to either the closest wireless access point (in a wireless local area network environment) or a base station (in a cellular network environment).

5. Wired networks: This component is optional for a mobile commerce system. However, most computers (servers) usually reside on wired networks such as the Internet, so user requests are routed to these servers using transport and/or security mechanisms provided by wired networks.

6. Host computers: Host computers process and store all the information needed for mobile commerce applications, and most application programs can be found here. They include three major components: Web servers, database servers, and application programs and support software.

\section{MOBILE HANDHELD DEVICES}

Mobile users interact with mobile commerce applications by using small wireless Internetenabled devices, which come with several aliases such as handhelds, palms, PDAs, pocket PCs, 
and smart phones. To avoid any ambiguity, a general term, mobile handheld devices, is used in this article. Mobile handheld devices are small general-purpose, programmable, battery-powered computers, but they are different from desktop PCs or notebooks due to the following special features:

- Limited network bandwidth,

- Small screen/body size, and

- Mobility.

Short battery life and limited memory, processing power, and functionality are additional features, but these problems are gradually being solved as the technologies improve and new methods are constantly being introduced. The limited network bandwidth prevents the display of most multimedia on a microbrowser. Though the Wi-Fi and 3G networks go some way toward addressing this problem, the wireless bandwidth is always far below the bandwidth of wired networks. The small screen/body size restricts most handheld devices to using a stylus for input. Figure 4 shows a typical system structure for handheld devices, which includes the following six major components: i) a mobile operating system, ii) a mobile central processing unit, iii) a microbrowser, iv) input/output devices, v) a memory, and vi) batteries. Brief descriptions of all the components follow, with more details in the next sections.

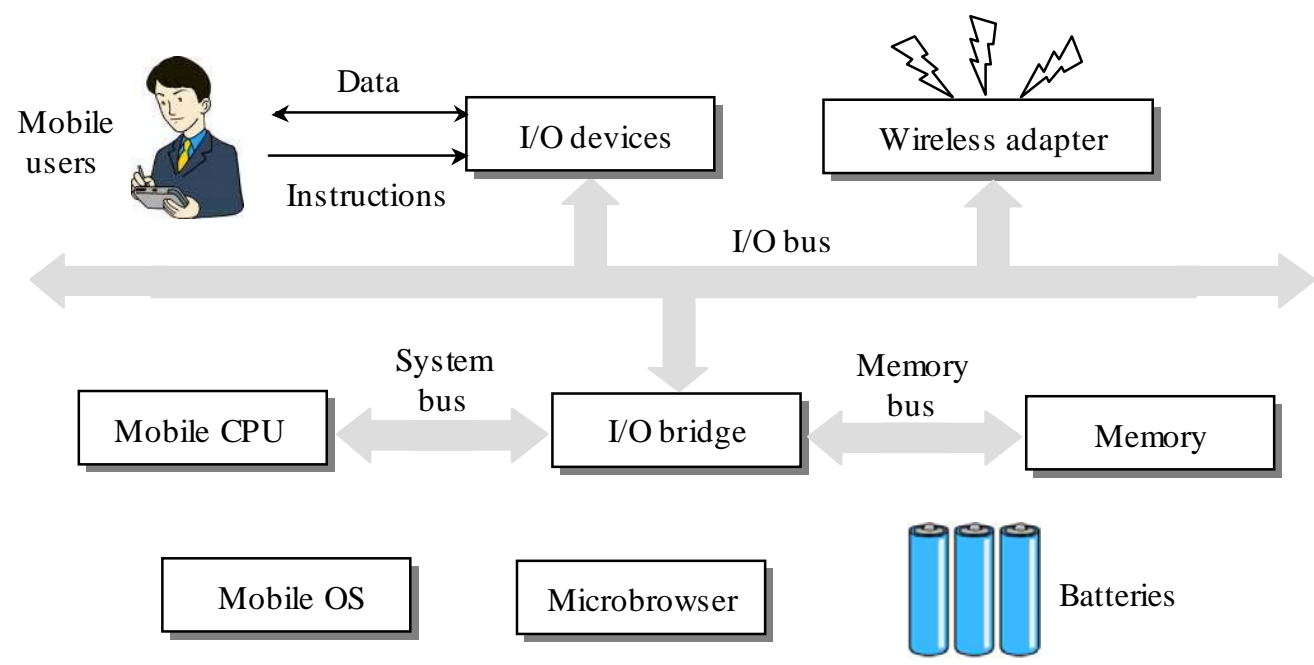

Figure 4: System structure of mobile handheld devices

1. Mobile operating systems: They are the core software of handheld devices. Mobile operating systems are different from those in desktop computers as they include the following additional features: i) power management to prolong the battery life, ii) real-time capability for time-critical operations such as voice communication, and iii) wireless infrastructure for wireless communication.

2. Mobile central processing units: Mobile CPUs are the core hardware of mobile handheld devices and the performance and functionality of the devices are heavily dependent on the capabilities of the processors. 
3. Microbrowsers: Microbrowsers are Internet browsers specifically designed for use in mobile handheld devices. They differ from desktop browsers in several ways, specifically the languages they use, security, footprint, and smaller windows. The last feature, smaller windows, enables them to provide simplified interfaces, although it also eliminates much of the desktop browser's multimedia functionality, such as streaming -audio and -video support.

4. Input/output devices: There is only one major output device, the screen, but there are several popular input devices, in particular keyboards and touch screens/writing areas that require the use of a stylus.

5. Memory: Three types of memory are usually employed by handheld devices: i) random access memory, ii) read-only memory, and iii) flash memory.

6. Batteries: Rechargeable Lithium Ion batteries are the most common batteries used by handheld devices.

\section{Major Devices}

Mobile handheld devices are usually divided into two types:

Figure 5: Sony Ericsson ${ }^{\circledR}$ P800

- Smart cellular phones: They are voice-based devices with data-processing capability. An example is the Sony Ericsson P800, shown in Figure 5, which is basically a cellular phone with a built-in camera, speakerphone, Bluetooth and IR connectivity, wireless e-mail and Internet access, and MP3 audio and MPEG-4 video capability. It can be synchronized with Microsoft Outlook via the included USB docking station.

- PDAs (Personal Digital Assistants): In contrast to smart cellular phones these are data-based devices, although they usually also have voice capability. Advanced PDAs provide the functions of telephone/fax, e-mails, PIM (personal information managers) such as calendars and address books, and networking features. A typical example is the Palm Tungsten $\mathrm{C}$, shown in Figure 6, which includes features such as built-in $\mathrm{Wi}-\mathrm{Fi}$, an integrated keyboard, email and Internet access, a transflective screen, and a $400 \mathrm{MHz}$ processor.

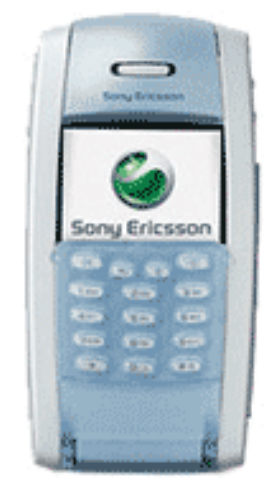

Figure 6: Palm ${ }^{\circledR}$ Tungsten $C$

These two kinds of devices started out as very different products, but they have gradually blended into each other. In the near future, it will be difficult to tell the difference between these two types of device. The newest products such as tablet PCs belong to the category of PDAs because both have similar functionality. 
There are numerous mobile devices available in the market today. Table 2 lists some major mobile device specifications, although several table entries are incomplete as some of the information is classified as confidential due to business considerations.

Table 2: Specifications of some major mobile handheld devices

\begin{tabular}{|c|c|c|c|c|c|}
\hline $\begin{array}{l}\text { Vendor \& } \\
\text { Device }\end{array}$ & $\begin{array}{l}\text { Operating } \\
\text { System }\end{array}$ & Processor & $\begin{array}{c}\text { Installed } \\
\text { RAM/ROM }\end{array}$ & $\begin{array}{l}\text { Input } \\
\text { Methods }\end{array}$ & $\begin{array}{l}\text { Key } \\
\text { Features }\end{array}$ \\
\hline $\begin{array}{l}\text { Compaq iPAQ } \\
\text { H3870 }\end{array}$ & $\begin{array}{l}\text { MS Pocket } \\
\text { PC } 2002\end{array}$ & $\begin{array}{l}206 \mathrm{MHz} \text { Intel } \\
\text { StrongARM 32-bit } \\
\text { RISC }\end{array}$ & $64 \mathrm{MB} / 32 \mathrm{MB}$ & Touchscreen & $\begin{array}{l}\text { Wireless } \\
\text { email/Internet }\end{array}$ \\
\hline $\begin{array}{l}\text { Handspring } \\
\text { Treo } 300\end{array}$ & $\begin{array}{l}\text { Palm OS } \\
\text { 3.5.2H }\end{array}$ & $\begin{array}{l}33 \mathrm{MHz} \text { Motorola } \\
\text { Dragonball VZ }\end{array}$ & $16 \mathrm{MB} / 8 \mathrm{MB}$ & $\begin{array}{l}\text { Keyboard/ } \\
\text { Stylus }\end{array}$ & CDMA network \\
\hline $\begin{array}{l}\text { Motorola } \\
\text { Accompli } 009\end{array}$ & $\begin{array}{l}\text { Wisdom } \\
\text { OS } 5.0\end{array}$ & $\begin{array}{l}33 \mathrm{MHz} \text { Motorola } \\
\text { Dragonball VZ }\end{array}$ & $8 \mathrm{MB} / 4 \mathrm{MB}$ & Keyboard & GPRS network \\
\hline $\begin{array}{l}\text { Nokia } 9290 \\
\text { Communicator }\end{array}$ & $\begin{array}{l}\text { Symbian } \\
\text { OS }\end{array}$ & 32-bit ARM9 RISC & $16 \mathrm{MB} / 8 \mathrm{MB}$ & Keyboard & WAP \\
\hline Nokia 6800 & Series 40 & & & Keyboard & $\begin{array}{l}\text { Innovative } \\
\text { keyboard } \\
\text { integration }\end{array}$ \\
\hline Palm i705 & $\begin{array}{l}\text { Palm OS } \\
4.1\end{array}$ & $\begin{array}{l}33 \mathrm{MHz} \text { Motorola } \\
\text { Dragonball VZ }\end{array}$ & $8 \mathrm{MB} / 4 \mathrm{MB}$ & Stylus & $\begin{array}{l}\text { Wireless } \\
\text { Email/Internet }\end{array}$ \\
\hline $\begin{array}{l}\text { Samsung SPH- } \\
\text { i330 }\end{array}$ & $\begin{array}{l}\text { Palm OS } \\
4.1\end{array}$ & $\begin{array}{l}\text { 66MHz Motorola } \\
\text { Dragonball Super } \\
\text { VZ }\end{array}$ & $16 \mathrm{MB} / 8 \mathrm{MB}$ & $\begin{array}{l}\text { Touchscreen/ } \\
\text { Stylus }\end{array}$ & Color screen \\
\hline $\begin{array}{l}\text { Sony Clie PEG- } \\
\text { NR70V }\end{array}$ & $\begin{array}{l}\text { Palm OS } \\
4.1\end{array}$ & $\begin{array}{l}66 \mathrm{MHz} \text { Motorola } \\
\text { Dragonball Super } \\
\text { VZ }\end{array}$ & $16 \mathrm{MB} / 8 \mathrm{MB}$ & $\begin{array}{l}\text { Keyboard/ } \\
\text { Stylus/ } \\
\text { Touchscreen }\end{array}$ & Multimedia \\
\hline $\begin{array}{l}\text { Sony Ericsson } \\
\text { T68i }\end{array}$ & & & $800 \mathrm{~KB}$ & Keyboard & $\begin{array}{l}\text { Multimedia } \\
\text { Messaging } \\
\text { Service } \\
\end{array}$ \\
\hline Toshiba E740 & $\begin{array}{l}\text { MS Pocket } \\
\text { PC } 2002\end{array}$ & $\begin{array}{l}400 \mathrm{MHz} \text { Intel } \\
\text { PXA250 }\end{array}$ & $64 \mathrm{MB} / 32 \mathrm{MB}$ & $\begin{array}{l}\text { Stylus/ } \\
\text { Touchscreen }\end{array}$ & $\begin{array}{c}\text { Wireless } \\
\text { Internet }\end{array}$ \\
\hline
\end{tabular}

\section{MOBILE OPERATING SYSTEMS}

Simply adapting desktop operating systems for mobile handheld devices has proved to be a futile endeavor; an example of this effort is Microsoft Windows CE. A mobile operating system needs a new architecture and different features in order to provide adequate services for handheld devices. This section presents a mobile operating system structure and discusses some major systems. 


\section{System Structure}

Several mobile operating systems are already available and each employs a different architecture and implementation. Figure 7 shows a generalized mobile operating system structure, which can be visualized as a six-layer stack:

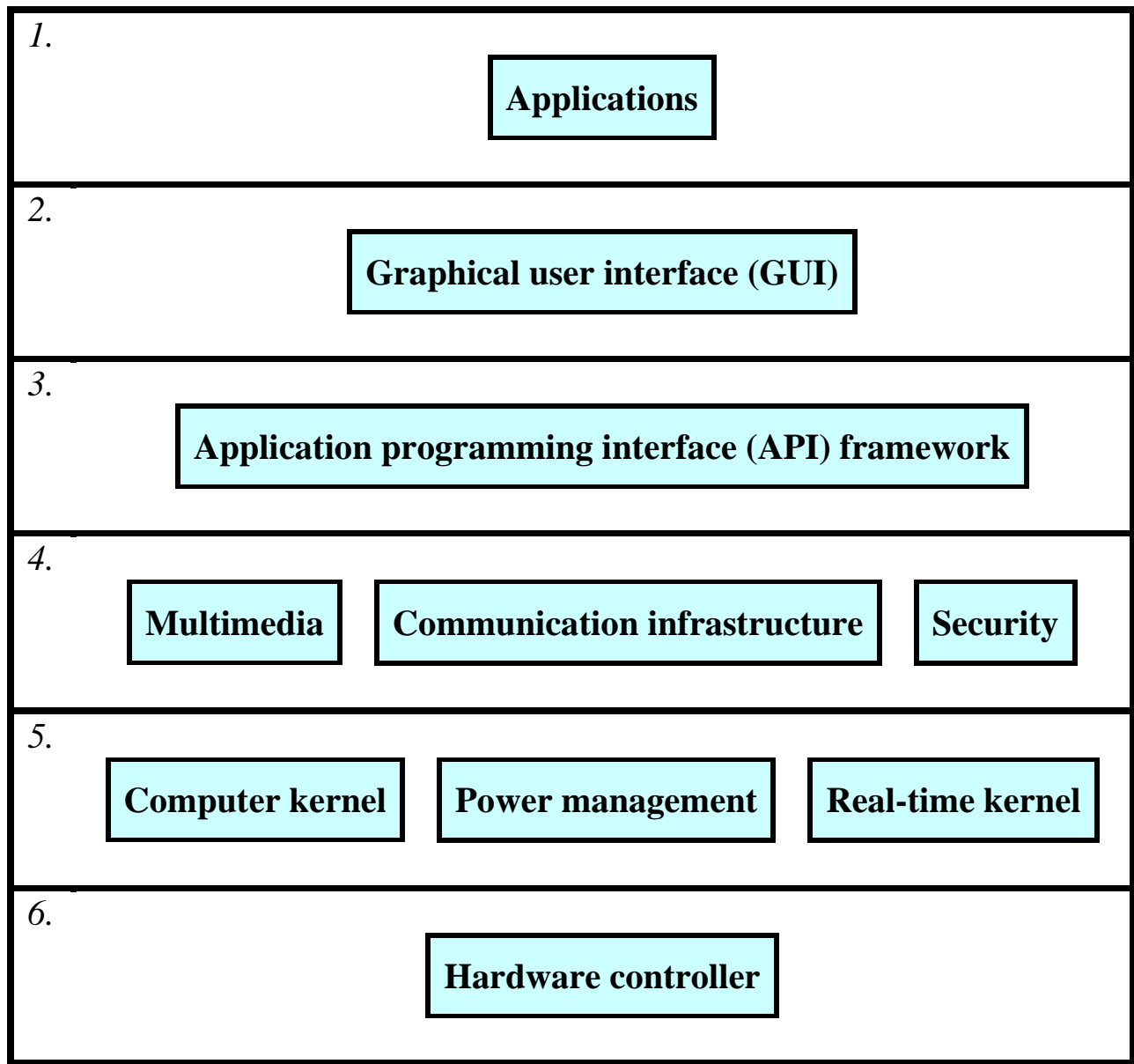

Figure 7: A generalized mobile operating system structure

1. Mobile applications: This level refers to customer-level applications such as microbrowsers and mobile retailing. Details of various mobile applications will be given in a later section.

2. Graphical user interface (GUI): Applications use the API to display information on the GUI, which is more limited in a mobile operating system than the GUI in a desktop OS.

3. Application programming interface (API) framework: This level provides the framework between the low-level architecture components and the application layer. By using this framework, application developers do not need to know the underlying low-level details in order to take full advantage of their capabilities.

4. This level consists of three components: 
- Multimedia: Widely adopting multimedia is one of the reasons for the success of electronic commerce. The same can be applied to mobile commerce, in particular more and more smart cellular phones are equipped with cameras. This module involves image/video related functionality, audio recording and play back, etc.

- Communication infrastructure: Wireless and mobile networks make a crucial difference between mobile commerce and electronic commerce. This module may contain widearea networking stacks including TCP/IP and WAP, personal area networking stacks including infrared (IrDA), Bluetooth, and USB, abstract API for cellular standards, and GSM and CDMA circuit-switched voice and data and packet-based data.

- Security: Security in mobile commerce is more vulnerable than in electronic commerce generally since mobile commerce communication is through wireless and mobile networks, which are more exposed to attacks. Mobile commerce security involves a wide variety of technologies, including authentication, cryptography, secure communications, secure mobile payment methods, etc.

5. The $5^{\text {th }}$ level also consists of three components:

- Computer kernel: This is the central module of an operating system and it provides all the essential services required by the other parts of the operating system and applications. For example, it is responsible for resource allocation, low-level hardware interfaces, and process and task management, etc.

- Power management: Battery life is short. This component manages the power consumption to prolong the battery life.

- Real-time kernel: This component is not required for desktop PCs because they can usually take a few seconds, or even minutes, to react. Mobile handheld devices need real-time responses for some time-critical applications such as voice communication.

6. The bottom level is the hardware controller. The hardware includes displays and memory. It is expected that hard disks will be added to the list in the near future.

\section{Major Systems}

Although a wide range of mobile handheld devices are available in the market, the operating systems, the hub of the devices, are dominated by just three major organizations. The following two lists show the operating systems used in the top three brands of smart cellular phones and PDAs in descending order of market share:

- Smart cellular phones: Microsoft Smartphone 2002, Palm OS 5, and Symbian OS 7. (VaughanNichols, 2003)

- PDAs: Palm OS 5, Microsoft Pocket PC 2002, and Symbian OS 7. (PCTechGuide, 2003)

The market share is changing frequently and claims concerning the share vary enormously. It is almost impossible to predict which will be the ultimate winner in the battle of mobile operating systems. The following four sub-sections briefly describe the above four systems in turn.

\section{Palm OS}

Palm OS (Palm Source, Inc., 2003) runs on almost two out of every three PDAs. Its popularity can be attributed to its many advantages, such as its long battery life, support for a 
wide variety of wireless standards, and the abundant software available. The plain design of the Palm OS has resulted in a long battery life, approximately twice that of its rivals. It supports many important wireless standards, including Bluetooth and 802.11b local wireless and GSM, Mobitex, and CDMA wide-area wireless networks. The type of software often used on PCs is gradually becoming available for Palm OS such as spreadsheets, databases, document processors, messaging programs, and multimedia tools. To offset the increasing challenge from Pocket PC 2002, Palm introduced Palm OS 5, which runs an ARM processor, has a high-resolution (320×320) color screen, $16 \mathrm{MB}$ of memory, and built in voice recorder, directional pad, built-in Bluetooth and media playback capability (MP3/OGG/WAV), and is complete with a speaker and headphone jack.

\section{Microsoft Smartphone}

The Smartphone (Microsoft Corp., 2003b) functions include: voice, SMS, and instant messaging services; email that can be received from sources such as the Outlook messaging and collaboration client, Exchange, IMAP, and POP3 services; and personal information management (PIM) applications such as calendar and contacts. The Smartphone 2002 platform is based on the Microsoft Windows CE 3.0 operating system, and contains many of the same core applications that are available on Pocket PC-based computing devices, including email, PIM tools, and Pocket Internet Explorer Web software. The primary Smartphone architecture consists of four layers:

- Applications/UI: The top level refers to the Smartphone shell and customer-level applications such as Pocket Internet Explorer, the Inbox, the control panel, and the phone dialer.

- Logic: This level contains system application logic that can be used by the application layer. Examples of this include the control of network connections and synchronization capabilities.

- Core APIs: This level provides the interfaces between the low-level architecture components (Operating System, Smartphone software, and radio stack) and the application/logic layers.

- Radio Stack: The bottom level refers, in general, to the architectural components responsible for voice and data control and data transmission.

\section{Microsoft Pocket PC}

In 1996, Microsoft launched Windows CE, a version of the Microsoft Windows operating system designed specially for a variety of embedded products, including mobile stations. However, it was not well received primarily because of battery-hungry hardware and limited functionality, possibly due to the way that Windows CE was adapted for mobile stations from other Microsoft 32-bit desktop operating systems. To compete with Palm OS, Microsoft later introduced Pocket PC (Microsoft Corp., 2003a), which was designed with better service for mobile users in mind and offers far more computing power than Windows CE. Moreover, the latest version introduces support for Bluetooth, IEEE 802.11b, and mobile phone technologies such as CDPD, CDMA, and GSM, and allows access to corporate information via a number of connectivity options, including VPN, WAN, LAN, and PANs. 


\section{Symbian OS}

EPOC16 from Psion Software is a 16-bit version of an operating system that has been available for several years and is embedded in many mobile stations; EPOC32 is a 32-bit open operating system that supports preemptive multitasking. In mid-1998, Psion joined forces with Ericsson, Nokia, and Motorola to form a new joint venture called Symbian OS (Dixon, 2003), with the aim of establishing EPOC as the de facto operating system for mobile stations. Unlike Windows CE, it was planned from the beginning to be a full operating system of mobile stations. It includes the following key features: integrated multimode mobile telephony, an open application environment, multi-tasking, multimedia, and data synchronization.

\section{MOBILE CENTRAL PROCESSING UNITS}

The core hardware in mobile handheld devices is the mobile processors, and the performance and functionality of the devices are largely dependent on the capabilities of the processors. There used to be several brands available, but recently mobile processors designed by ARM Ltd. have begun to dominate the market.

\section{Requirements of a Mobile CPU}

Handheld devices are becoming more sophisticated and efficient every day and mobile users are demanding more functionality from the devices. For example, in 2002 In-Stat/MDR predicted that worldwide mobile Internet access device unit shipments would increase from approximately 430 million that year to approximately 760 million in 2006 (In-Stat/MDR, 2002). To achieve this advanced functionality, in addition to the obvious feature, low cost, today's mobile processors must have the following features:

- High performance: The clock rate must be higher than the typical $30 \mathrm{MHz}$ for Palm OS PDAs, $80 \mathrm{MHz}$ for cellular phones, and $200 \mathrm{MHz}$ for devices that run Microsoft's Pocket PC.

- Low power consumption: This prolongs battery life and prevents heat buildup in handheld devices that lack the space for fans or other cooling mechanisms.

- Multimedia capability: Audio/image/video applications are recurring themes in mobile commerce.

- Real-time capability: This feature is particularly important for time-critical applications such as voice communication.

\section{ARM Processors}

A few mobile processors such as Motorola Dragonball and Intel Pentium M were designed, manufactured, and sold by chip-making companies such as Motorola, Intel, and Texas Instruments. Now, however, the cores and architectures designed by Cambridge-based ARM Holdings Ltd. have begun to dominate the market. ARM is the industry's leading provider of 16/32-bit embedded RISC microprocessor solutions. The company does not actually produce chips, but instead licenses its RISC processors, peripherals, and system-chip designs to electronics companies. ARM's microprocessor cores specifically address the needs of advanced operating systems, real-time, and multimedia applications. 


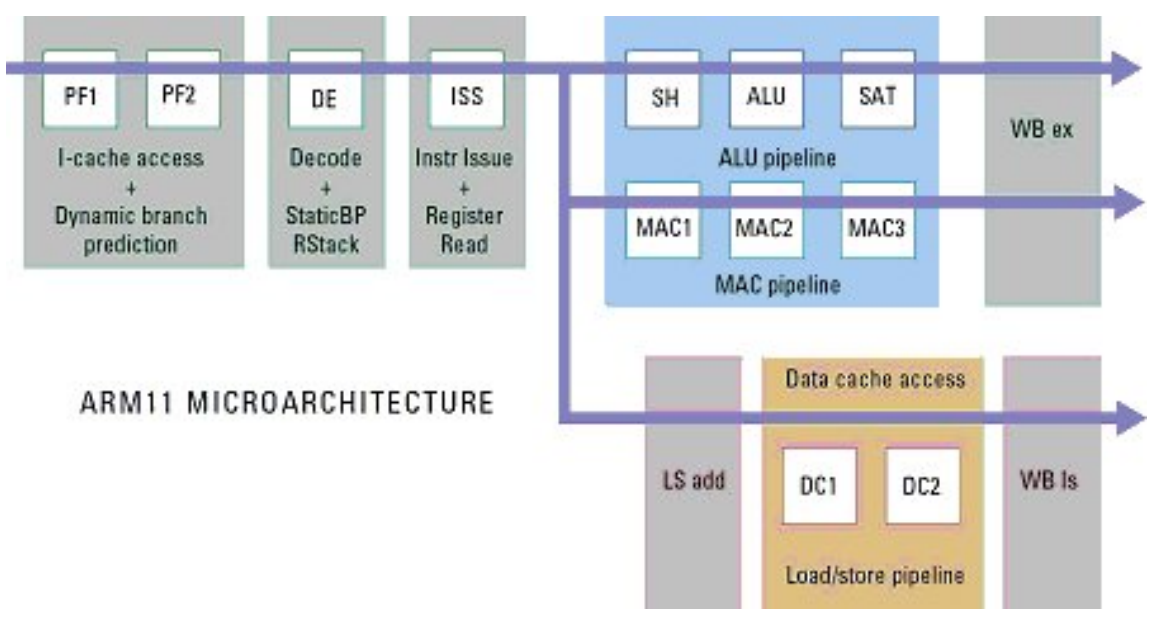

Figure 8: ARM11 microarchitecture, ㄷ 2003 ARM, Ltd. Reprinted with permission

Figure 8 shows the ARM11 pipeline structure. This is the first implementation of the ARMv6 instruction set architecture (ISA), and was developed specifically with the needs of next-generation consumer, wireless, networking, automotive products, and consumerentertainment applications in mind (Cormie, 2003). The ARM11 microarchitecture targets a 330-400 MHz worst case on $0.13 \mu \mathrm{m}$ foundry processes, delivering 400 to 500 Dhrystone MIPS. The ARM11 microarchitecture was designed to meet the low power requirement of batterypowered and high-density embedded applications, consuming less than $0.4 \mathrm{~mW} / \mathrm{MHz}$ on $0.13 \mu \mathrm{m}$ foundry processes. In addition to supporting 32-bit ARMv6 ISA, it has the following features:

- $\quad$ Supporting Thumb 16-bit instruction set,

- ARM DSP extensions,

- SIMD (Single Instruction Multiple Data) media processing extensions deliver up to $2 \times$ performance for audio and video processing,

- Better power/performance trade-off $(0.4 \mathrm{~mW} / \mathrm{MHz}$ in $0.13 \mu \mathrm{m})$,

- An 8-stage integer pipeline improving performance,

- Separate load-store and arithmetic pipelines,

- A 64-bit memory system speeding data access,

- Speedy interrupt response and real-time performance, and

- Vector Floating Point coprocessor for automotive controls and 3D graphics acceleration.

\section{MICROBROWSERS}

Microbrowsers are a miniaturized version of desktop browsers such as Netscape Navigatorsand Microsoft Internet Explorers. They provide graphical user interfaces that enable mobile users to interact with mobile commerce applications.

\section{Features}

Due to the limited resources of handheld devices, microbrowsers differ from traditional desktop browsers in the following ways: 
- smaller windows,

- smaller footprints, and

- fewer functions and multimedia features.

Several microbrowsers, such as Microsoft Mobile Explorer and Wapaka Java MicroBrowser, are already available. America Online, Inc., the parent company of the Netscape Network, and Nokia are developing and marketing a Netscape-branded version of Nokia's WAP microbrowser, with AOL enhanced features, for use across a wide variety of mobile handheld devices. Figure 9 shows a typical microbrowser, a Mobile Browser version 7.0 from Openwave Systems, which includes the following features: compatibility with WAP or i-mode, multimedia support, color images and animation, and dual network stack, HTTP and WSP, support (Openwave Systems Inc., 2003).

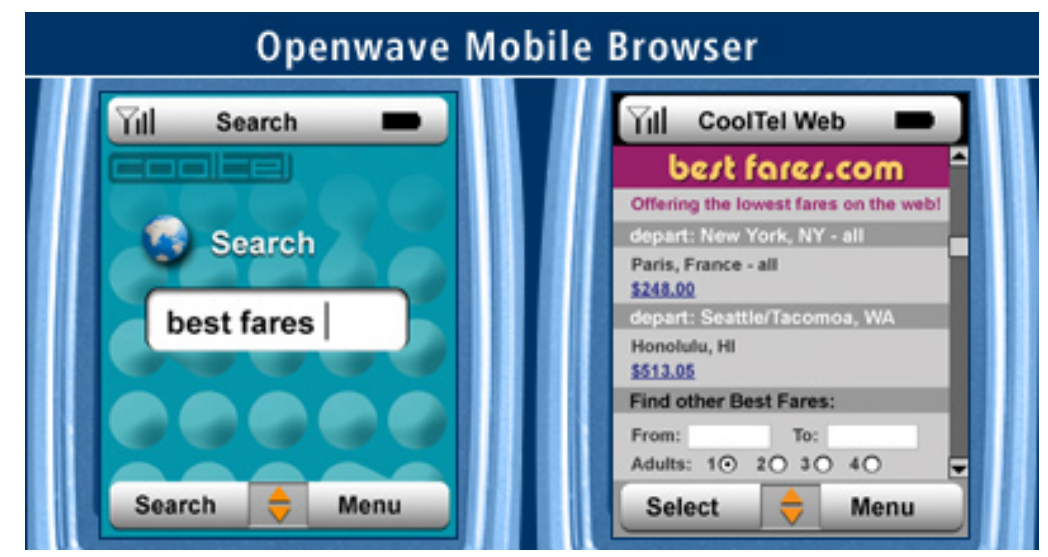

Figure 9: Openwave ${ }^{\circledR}$ Mobile Browser version 7

\section{Technologies}

Several markup languages are used to present mobile contents on microbrowsers. These may not be able to handle all the languages currently used, therefore certain contents may not be displayed by some microbrowsers. Microbrowsers usually take the following four approaches, as shown in Figure 10, to display mobile contents (Lawton, 2001):

1. Wireless language direct access: A microbrowser supports some kinds of wireless languages, such as WML, CHTML, and XML, and directly displays the contents written in a wireless language supported by that microbrowser.

2. HTML direct access: This approach displays the HTML contents directly with, no intervention, but it may distort the contents. For example, large images can not be displayed on the small screens of microbrowsers.

3. HTML to wireless language conversion: Some mobile middleware provides conversion software to convert an HTML script to a script of the wireless language supported by that microbrowser. For example, i-mode includes a Corporate Conversion Server that converts existing HTML files into i-mode-compatible HTML, the CHTML. 
4. Error: If the microbrowsers are not able to handle the contents, they simply display an error code such as "Invalid WML code."

Some microbrowsers, like most desktop browsers, can automatically send and receive information via cache, which is known as Web caching (Davison, 2001). Web caching has significant advantages such as reduced bandwidth consumption, server load, and latency. Together, the advantages make the Web less expensive and improve its performance.

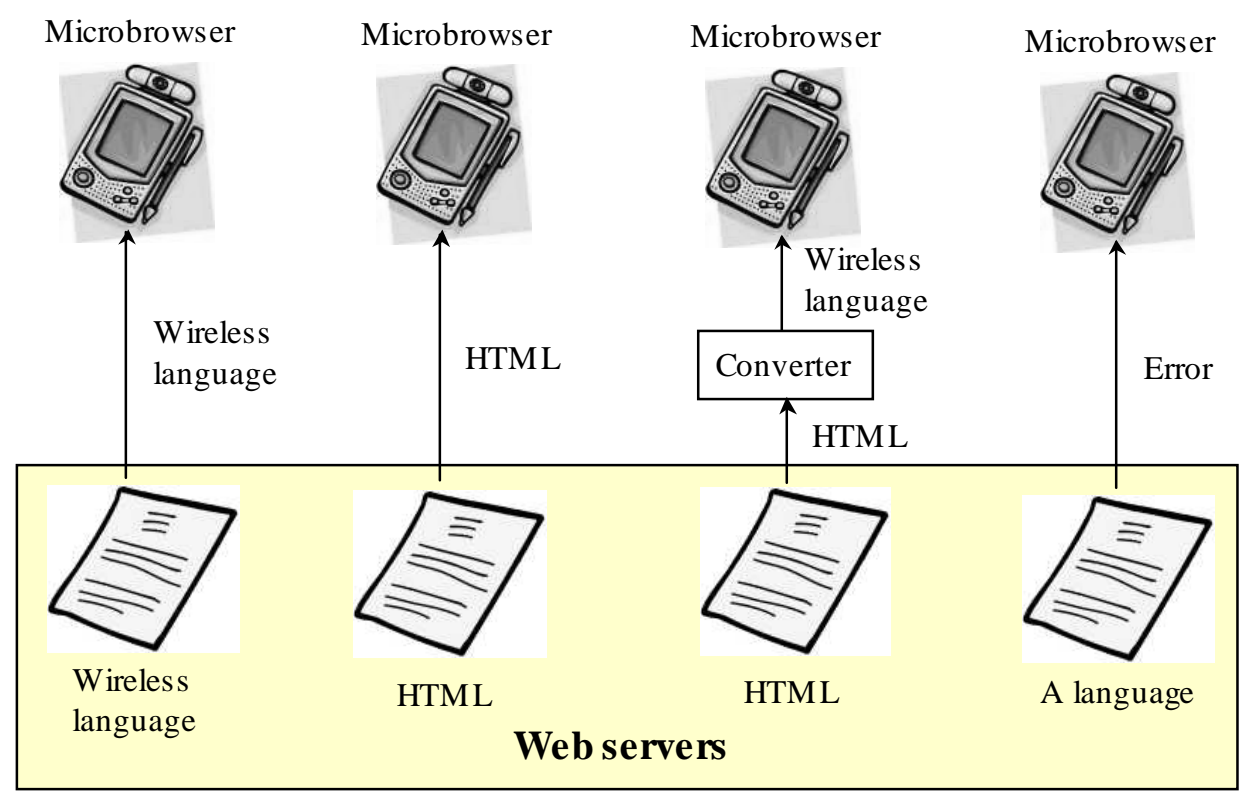

Figure 10: Four approaches for microbrowsers to display mobile contents

\section{INPUT/OUTPUT DEVICES, MEMORY, BATTERIES, AND SYNCHRONIZATION}

The three components of mobile handheld devices, mobile OSs, mobile CPUs, and microbrowsers, result in a significant difference between handheld devices and desktop PCs. However, the remaining components do not play such a crucial role. This section briefly introduces the remaining components of handheld devices, which include: i) input/output devices, ii) memory, and iii) batteries, as well as synchronization with desktop PCs, notebooks, and other peripheral devices.

\section{Input/Output Devices}

Various I/O devices have been adopted by mobile handheld devices. The only major output device is the screen, whereas there are several popular input devices, including:

- Keyboards: There are two kinds of keyboards: built-in keyboards and external, plug-in keyboards. The problem with the former is that they are too small for touch-typing, whereas the latter suffers from inconvenience. Fabric keyboards that can be rolled up or folded 
around the handheld devices are being developed to relieve the problem of external keyboards.

- Touch screens/writing areas with a stylus: A touch screen is a display that is sensitive to human touch, allowing a user to interact with the applications by touching pictures or words on the screen, and a stylus is an input device used to write text or draw lines on a surface as input to a handheld device. A handheld device equipped with a writing area and a stylus needs a handwriting recognition function, but existing systems do not yet have a satisfactory recognition rate. Graffiti, employed by many handheld devices, is the most popular writing software.

Some mobile handheld devices can also react to voice input by using voice recognition technology.

\section{Memory}

Desktop PCs or notebooks usually have between 64 to 256 Mbytes of memory available for users, whereas handheld devices typically have only 4 to 64 Mbytes. PDAs normally have more storage space than smart cellular phones. The former commonly have 16 Mbytes, and the latter may have a memory size as low as a few Kbytes. Three types of memory are usually employed by handheld devices:

- Random access memory (RAM): There are two basic types of RAM, dynamic RAM (DRAM) and static RAM (SRAM). Dynamic RAM, the more common type, needs to be refreshed thousands of times per second in order to hold data, whereas static RAM does not need to be refreshed, making it faster but also more expensive than dynamic RAM. Both types of RAM are volatile; i.e., they do not retain their contents when the power is switched off.

- Read-only memory (ROM): ROM is manufactured with fixed contents, and it is usually used to store the programs that boot the device and perform diagnostics. It is inherently nonvolatile storage, in contrast to RAM.

- Flash memory: This is a kind of non-volatile storage similar to EEPROM (electrically erasable programmable read-only memory), but updating can only be done either in blocks or for the entire chip, making it easy to update. Flash memory is not as useful as random access memory because RAM can be addressable down the byte (rather than the block) level.

It is expected that hard disks, which provide much more storage capacity, will be adopted by handheld devices in the near future. A comprehensive survey of storage options can be found in Scheible (2002).

\section{Batteries}

Rechargeable Lithium Ion batteries are the batteries most commonly used by handheld devices. The life of this kind of battery is short, generally only a few hours of operating time. Battery technology will not significantly improve unless and until manufacturers begin to switch to fuel cells, which is unlikely in the near future. A fuel cell operates like a battery, but unlike a battery, a fuel cell does not run down or require recharging and will continue to produce energy in the form of electricity and heat as long as fuel is supplied. Since the fuel cell relies on chemical energy rather than combustion, emissions would be much lower than emissions from the cleanest existing fuel combustion processes. 


\section{Synchronization}

Synchronization connects handheld devices to desktop computers, notebooks, and peripherals in order to transfer or synchronize data. The traditional method of synchronization uses serial cables to connect handheld devices and other computing equipment. Now, however, many handheld devices use either an infrared (IR) port or Bluetooth technology to send information to other devices without needing to use cables:

- IrDA Data (Infared Data Association, 2003), a standard formulated by the Infrared Data Association to ensure the quality and interoperability of infrared hardware, is designed for data transfer over distances of up to one meter, acting as a point-to-point cable replacement.

- Bluetooth wireless technology is a specification aiming at simplifying communications among handheld devices, printers, computers, and other devices based on short-range radio technology. The Bluetooth 1.1 specifications (Bluetooth SIG, Inc., 2003) consist of two documents: the Core, which provides design specifications, and the Profile, which provides interoperability guidelines.

\section{MOBILE COMMERCE APPLICATIONS}

The applications of electronic commerce are already widespread; mobile commerce applications not only cover these existing transactions but also include new ones. For example, some tasks that are not feasible for electronic commerce, such as mobile inventory tracking and dispatching, are possible for mobile commerce. This section will discuss these new applications and explore the new opportunities that are arisen from this new area.

\section{Categories of Mobile Commerce Applications}

Table 3 lists the major mobile commerce applications (Gordon \& Gebauer, 2001; Sadeh, 2002), along with details of each.

Table 3: Major mobile commerce applications

\begin{tabular}{|l|l|l|}
\hline Mobile Category & \multicolumn{1}{|c|}{ Major Applications } & \multicolumn{1}{|c|}{ Clients } \\
\hline Commerce & Mobile transactions and payments & Business \\
\hline Education & Mobile classrooms and labs & Schools and training centers \\
\hline $\begin{array}{l}\text { Enterprise resource } \\
\text { planning }\end{array}$ & Resource management & All \\
\hline Entertainment & $\begin{array}{l}\text { Games/images/music/video downloads and on- } \\
\text { line gaming }\end{array}$ & Entertainment industry \\
\hline Health care & Accessing and updating patient records & Hospitals and nursing homes \\
\hline $\begin{array}{l}\text { Inventory tracking and } \\
\text { dispatching }\end{array}$ & Product tracking and dispatching & $\begin{array}{l}\text { Delivery services and } \\
\text { transportation }\end{array}$ \\
\hline Traffic & $\begin{array}{l}\text { Global positioning, directions, and traffic } \\
\text { advisories }\end{array}$ & $\begin{array}{l}\text { Transportation and auto } \\
\text { industries }\end{array}$ \\
\hline Travel and ticketing & Travel management & $\begin{array}{l}\text { Travel industry and ticket } \\
\text { sales }\end{array}$ \\
\hline
\end{tabular}




\section{Commerce}

Commerce is the exchange or buying and selling of commodities on a large scale involving transportation of goods from place to place. It is boosted by the convenience and ubiquity conveyed by mobile commerce technology. There are many examples showing how mobile commerce helps commerce. For example, consumers can buy products from a vending machine or pay a parking fee by using their cellular phones, and mobile users can check their bank accounts and perform account balance transfers without needing to go to a bank or access an ATM.

\section{Education}

Many schools and colleges are facing problems due to a shortage of computer lab space, separation of classrooms and labs, and the difficulty of remodeling old classrooms for wired networks. To relieve these problems, wireless LANs are often used to hook PCs or mobile handheld devices to the Internet and other systems. As a result, students are able to access many of the required resources without taking up valuable lab space.

\section{Enterprise Resource Planning (ERP)}

ERP is an industry term for the broad set of activities supported by the type of multi-module application software that assists a manufacturer or other organization manage important aspects of its business, including product planning, purchasing parts, maintaining inventories, interacting with suppliers, providing customer service, and tracking orders. The ERP issues that are particularly relevant to mobile commerce include tracking the location of goods and services, locating specific items, and transmitting warnings about aging components.

\section{Entertainment}

Entertainment has always played a crucial role in Internet applications and is probably the most popular application for the younger generation. Mobile commerce makes it possible to download game/image/music/video files at anytime and anywhere, and it also makes on-line games and gambling much easier to access and play. It is projected that by 2005, 80 percent of all mobile users in the United States and Western Europe will play mobile games at least occasionally (Leavitt, 2003).

\section{Health Care}

The cost of health care is high and mobile commerce can help to reduce it. By using the technology of mobile commerce, physicians and nurses can remotely access and update patient records immediately, a function which has often incurred a considerable delay in the past. This improves efficiency and productivity, reduces administrative overheads, and enhances overall service quality.

\section{Inventory Tracking and Dispatching}

Just-in-time delivery is critical for the success of today's businesses. Mobile commerce allows a business to keep track of its mobile inventory and make time-definite deliveries, thus improving customer service, reducing inventory, and enhancing a company's competitive edge. Major delivery services such as UPS and FedEx have already applied these technologies to their 
business operations worldwide with great success.

\section{Traffic}

Traffic is the movement of vehicles or pedestrians through an area or along a route. The passengers in the vehicles and the pedestrians are all mobile objects, ideal clients of mobile commerce. Also, traffic control is usually a major headache for many metropolitan areas. Using the technology of mobile commerce can easily improve the flow of traffic in many ways. For example, a mobile handheld device can have the capabilities of a GPS (Global Positioning System), such as determining the driver's exact position, giving directions, and advising on the current status of traffic in the area. A traffic control center could also monitor and control the traffic according to the signals sent from mobile devices in the vehicles.

\section{Travel and Ticketing}

Travel expenses can be costly for a business. Mobile commerce could help reduce operational costs by providing mobile travel management services to business travelers. It can be used to provide assistance to customers by using the mobile channels to locate a desired hotel nearby, purchase tickets, make transportation arrangements, and so on. It also extends the reach of relationship-oriented companies beyond their current channels and helps the mobile users to identify, attract, serve, and retain valuable customers.

\section{SUMMARY}

The emerging wireless and mobile networks have extended electronic commerce to another research and application area: mobile commerce. Internet-enabled mobile handheld devices are one of the core components of mobile commerce systems, as they are needed for mobile users to directly interact with mobile commerce applications. Understanding the devices and knowing their functions and capabilities is vital for the success of mobile commerce applications. A handheld device relies on a wide range of disciplines and technologies for its success. To facilitate the understanding, this paper broke down the functions of a handheld device into six major components, which can be summarized as follows:

1. Mobile operating systems: Simply adapting desktop operating systems for handheld devices has proved to be futile. A mobile operating system needs a completely new architecture and different features to provide adequate services for handheld devices. A generalized mobile operating system structure can be visualized as a six-layer stack: i) applications, ii) GUI, iii) API framework, iv) multimedia, communication infrastructure, and security, v) computer kernel, power management, and real-time kernel, and vi) hardware controller.

2. Mobile central processing units: Handheld devices are becoming more sophisticated and efficient every day and mobile users are demanding more functionality from their devices. To achieve this advanced functionality, in addition to the obvious feature, low cost, today's mobile processors must have the following features: i) high performance, ii) low power consumption, iii) multimedia capability, and iv) real-time capability. The cores and architectures designed by Cambridge-based ARM Holdings Ltd. have begun to dominate the mobile CPU market.

3. Microbrowsers: Microbrowsers are miniaturized versions of desktop browsers such as Netscape Navigator and Microsoft Internet Explorer. They provide graphical user interfaces 
that allow mobile users to interact with mobile commerce applications. Microbrowsers usually use one of the following four approaches to return results to the mobile user: i) wireless language direct access, ii) HTML direct access, iii) HTML to wireless language conversion, and iv) error.

4. Input/output devices: Various I/O devices have been adopted by mobile handheld devices. The only major output device is the screen, but there are several popular input devices, among them: i) keyboards and ii) touch screens/writing areas that need a stylus.

5. Memory: Three types of memory are usually employed by handheld devices: i) RAM, ii) ROM, and iii) flash memory. Hard disks, which provide much more storage capacity, are likely to be adopted by handheld devices in the near future.

6. Batteries: At present, rechargeable Lithium Ion batteries are the most common batteries used by handheld devices. However, the life of this kind of battery is short and the technology will not significantly improve unless and until manufacturers begin to switch to fuel cells, which may not happen for at least several years.

Synchronization connects handheld devices to desktop computers, notebooks, or peripherals to transfer or synchronize data. Without needing serial cables, many handheld devices now use either an infrared (IR) port or Bluetooth technology to send information to other devices. The applications of electronic commerce are already widespread and new mobile commerce applications are also becoming possible.

\section{REFERENCES}

Bluetooth SIG, Inc. (2003). Bluetooth specifications. Retrieved August 12, 2004 from https://www.bluetooth.org/foundry/specification/document/specification

Cormie, D. (2002). The ARM11 microarchitecture. Retrieved July 21, 2004 from http://www.arm.com/support/59XGYS/\$File/ARM11+Microarchitecture+White+Paper.pdf

Davison, B. D. (2001). A Web caching primer. IEEE Internet Computing, 5(4), 38-45.

Dixon, K. (2003). Symbian OS version 7.0s-Functional description. Retrieved August 13, 2004 from http://www.symbian.com/technology/SymbianOSv7.0s_funcdesc2.1.pdf

Eurotechnology Japan K. K. (2002). Frequently asked questions about NTT-DoCoMo's i-mode. Retrieved December 16, 2004 from http://www.eurotechnology.com/imode/faq.html

Geihs, K. (2001). Middleware challenges ahead. IEEE Computer, 34(6), 24-31.

Gordon, P. \& Gebauer, J. (2001). M-commerce: Revolution + inertia = evolution. Working Paper 01-WP-1038, University of California, Berkeley, California.

Hu, W., Lee, C., \& Yeh, J. (2003). Mobile commerce systems. In Shi, N. (Ed.), Wireless communications and mobile commerce. Idea Group, Inc.

Infared Data Association. (2003). Technical summary of "IrDA DATA" and "IrDA CONTROL.” Retrieved July 15, 2004 from http://www.irda.org/standards/standards.asp

In-Stat/MDR. (2002). Demand increasing for mobile Internet access devices-Handsets represent primary growth driver. Retrieved July 08, 2004 from http://www.instat.com/press.asp?ID=250\&sku=IN020280MD

Lawton, G. (2001). Browsing the mobile Internet. IEEE Computer, 35(12), 18-21.

Leavitt, N. (2003). Will wireless gaming be a winner? IEEE Computer, 36(1), 24-27.

Microsoft Corp. (2003a). Pocket PC. Retrieved June 25, 2004 from 
http://www.microsoft.com/windowsmobile/products/pocketpc/default.mspx

Microsoft Corp. (2003b). Smartphone. Retrieved June 23, 2004 from http://www.microsoft.com/windowsmobile/products/smartphone/default.mspx

NTT DoCoMo. (n.d.). i-mode. Retrieved June 28, 2004 from http://www.nttdocomo.com/

Openwave Systems Inc. (2003). Mobile Browser V7. Retrieved July 15, 2004 from http://www.openwave.com/products/device_products/phone_tools/mobile_browser_7.html

PCTechGuide. (2003). Mobile computing. Retrieved July 2, 2004 from http://www.pctechguide.com/25mobile.htm

PalmInfocenter.com. (2003). PDA market still poised for growth. Retrieved August 10, 2004 from http://www.PalmInfocenter.com/view_Story.asp?ID=5050

Palm Source, Inc. (2003). Palm OS. Retrieved December 22, 2004 from http://www.palmsource.com/palmos/

Reuters. (2001). The Yankee Group publishes U.S. mobile commerce forecast. Reuters. Retrieved June 16, 2004 from http://about.reuters.com/newsreleases/art_31-102001_id765.asp

Sadeh, N. (2002). M-commerce: Technologies, services, and business models (pp. 177-179). New York: John Wiley \& Sons.

Scheible, J. P. (2002). A survey of storage options. IEEE Computer, 35(12), 42-46.

Varshney, U., Vetter, R. J., \& Kalakota, R. (2000). Mobile commerce: A new frontier. IEEE Computer, 33(10), 32-38.

Vaughan-Nichols, S. J. (2003). OSs battle in the smart-phone market. IEEE Computer, 36(6), 10-12.

Wireless Application Protocol Forum Ltd. (n.d.). WAP (Wireless Application Protocol). Retrieved July 21, 2004 from http://www.wapforum.org/

The Yankee Group. (2002). Over 50\% of large U.S. enterprises plan to implement a wireless/mobile solution by 2003. Retrieved July 10, 2004 from http://www.yankeegroup.com/public/news_releases/news_release_detail.jsp?ID=PressRelea ses/news_09102002_wmec.htm 